\section{Российские и европейские стали для металлических сварных конструкций}

\author{
П. А. Малинен ${ }^{1}$ \\ О. В. Казачков \\ Б. Н. Ягнюк \\ Петрозаводский государственный университет
}

\begin{abstract}
АННОТАЦИЯ
Статья посвящена сравнительному анализу современных сталей для металлических сварных конструкций, широко используемых на территории России, стран Евросоюза, путем сравнения их по химическому составу и механическим свойствам по стандартам EN10025, EN10113, ГОСТ 27772. Приведены таблицы отечественных сталей с подбором аналогов зарубежных сталей.
\end{abstract}

Ключевые слова: сталь, металлические конструкции, прокат, структура.

\section{SUMMARY}

The article is devoted to the comparative analysis of modern steel materials used for welding steel structures and widely applied in Russia and European countries. They are compared by their chemical composition and mechanical properties according to standards EN 110025 , EN 10113, GOST 27772 and specifications.

Keywords: steel, welding structure, standard.

В производстве лесных машин и навесного оборудования широко применяются стали, предназначенные для металлических сварных конструкций. Например, в трелевочном тракторе - это рама, кронштейн крепления кабины к раме, каркас кабины, несущие детали манипулятора и т.п.

Отечественные стали для строительных металлических конструкций регламентируются ГОСТ 27772-88 «Прокат для строительных стальных конструкций. Общие технические условия». Он распространяется на листовой, широкополосный универсальный, фасонный (уголки, двутавры, швеллеры), сортовой прокат и гнутые профили из углеродистых и низколегированных сталей для стальных конструкций со сварными и другими соединениями.

Общеевропейские стали для сварных конструкций регламентируются стандартом EN 10025 (Hot rolled products of non-alloy structural steels. Technical delivery conditions). Стандарт определяет требования к горя-

\footnotetext{
${ }^{1}$ Авторы - соответственно доченты кафедры технологии металлов и ремонта и доцент кафедры архитектуры, строительных конструкиий и геотехни$\kappa u$

(C) П. А. Малинен, О. В. Казачков, Б. Н. Ягнюк, 2003
}

чекатаным нелегированным сталям обычного качества и качественным, поставляемым в виде листового и длинномерного проката. Поставляемые по стандарту стали предназначены для использования в сварных, болтовых и клёпаных конструкциях при климатических температурах. Термическая обработка для этих сталей не предусмотрена, не считая поставки в нормализованном состоянии $(\mathrm{N})$. Отпуск для снятия внутренних напряжений допускается.

Кроме этого, для металлоконструкций применяются свариваемые мелкозернистые стали, поставляемые по стандарту EN 10113 (части 1, 2, 3). Этот европейский стандарт определяет требования к прокату из качественных и специальных мелкозернистых свариваемых сталей. Эти стали, по сравнению с обычными нелегированными сталями, поставляемыми по стандарту EN 10025, имеют более высокие показатели прочности $(\operatorname{Re}, \operatorname{Rm})$, пластичности $(\delta)$, ударной вязкости $(\mathrm{KCV})$ и более низкую температуру перехода в хрупкое состояние $\left(t_{x p}\right)$.

Отличие отечественных высокопрочных сталей от европейских сталей заключается в основном в том, что в российских стандартах широко предусматривается использование низколегированных сталей (09Г2С, 10Г2С1Д, 10ХСНД и др.), тогда как в общеевропейских стандартах системы EN регламентируются высокопрочные низкоуглеродистые стали, у которых соответствующие механические свойства создаются за счет измельчения зерна и микролегирования низкоуглеродистых сталей. В связи с создавшейся дефицитностью основного легирующего элемента, применяемого в отечественном прокате повышенной прочности, предназначенном для сварных конструкций, а именно марганца (стали 09Г2, $10 Г 2 \mathrm{C} 1,12 Г 2 \mathrm{C}$ и др.), в последние годы разрабатываются металлургическими комбинатами страны микролегированные низкоуглеродистые стали на базе марки Ст3, которые имеют повышенную прочность и хладостойкость и могут применяться взамен марганцовистых сталей. Эти стали не вошли в ГОСТ 27772-88, а поставляются по разработанным металлургическими комбинатами техническим условиям, например [2, 3, 4 ].

Европейский стандарт EN 10113 определяет общие требования к мелкозернистым сталям повышенной категории качества. В части 2 этого стандарта даны марки и классы качества нормализованных сталей $(\mathrm{N})$ и условия их поставки; в части 3 - соответственно то же для сталей, подвергнутых термомеханической обработке (М). Механические свойства сталей по стандарту EN 10113 приведены в таблице 3.

Эти стали специально предназначены для производства тяжелонагруженных частей в таких конструкциях, как мосты, затворы шлюзов, складские хранилища, водонапорные башни и т.д. Указанные части конструкций работают при климатических или более низких отрицательных температурах. 
Специальные атмосферостойкие стали поставляются по европейскому стандарту EN 10155, а улучшаемые (закалка и высокий отпуск) мелкозернистые стали будут поставляться по стандарту pr EN 10149.

В отечественных строительных сталях по ГОСТ 27772 буквенные символы обозначают: С сталь строительная; К - вариант химического состава; Т - термическое упрочнение; цифра - предел текучести в МПа.

Величина предела текучести ( $\mathrm{Re})$ положена в основу классификации как основная расчетная и эксплуатационная характеристика проката для стальных конструкций. Она находится в корреляции с пределом прочности (Rm).

В большинстве зарубежных национальных стандартов в марке стали приводится значение минимального предела прочности Rm (например DIN 17100, SFS-200 и т.п.). Аналогично и в международном стандарте ISO 630.

В новых стандартах Европейского Союза системы $\mathrm{EN}$, как и в российском ГОСТ 27772, в марке стали приводится значение предела текучести Re. Поэтому базой для сравнения отечественных сталей и сталейаналогов по общеевропейским стандартам примем значение предела текучести Re.

Важнейшим эксплуатационным свойством сталей является сопротивление хрупкому разрушению, определяемое при сериальных испытаниях на ударный изгиб образцов размером 10x10x55 мм при понижающихся температурах испытания. В стандартах на металлопродукцию представлены гарантированные величины ударной вязкости (KCU, KCV) - ГОСТ 27772 или работы разрушения (KV) - стандарты EN. Гарантированное значение работы разрушения при определенных температурах испытания на ударный изгиб обозначают символами, приведенными в табл. 1. Если сталь прошла нормализацию у изготовителя, в том числе и нормализацию с прокатного нагрева, то в марке стали ставят обозначение $\mathrm{N}$, если сталь подвергнута термомехнической обработке обозначение М, прочие гарантируемые свойства обозначают буквой $\mathrm{G}$, дополненной при необходимости цифрами 1, 2 или 3, 4. Качество малоуглеродистых сталей существенно зависит от степени раскисления. В отечественных стандартах раскисление обозначается строчными буквами в конце марки: кп - кипящая сталь, пс - полуспокойная сталь, сп - спокойная сталь.

В европейских стандартах обозначение способа раскисления стали дается в конце марки буквами: FU нераскисленная сталь (кипящая); FF - раскисленная сталь (спокойная).

В массовых малоуглеродистых сталях степень раскисления является важным классификационным признаком.
В настоящем исследовании рассмотрены классы строительных конструкционных сталей по стандартам EN10025 и EN10113 и показано соответствие и отличие их от отечественных сталей для строительных конструкций, поставляемых по ГОСТ 27772:

- по химическому составу;

- по показателям прочности и пластичности;

- по ударной вязкости.

Таблица 1

Обозначение гарантированной вязкости в наименовании сталей

\begin{tabular}{|c|c|c|c|}
\hline $27 \mathrm{~J}$ & $40 \mathrm{~J}$ & $60 \mathrm{~J}$ & ${ }^{\circ} \mathrm{C}$ \\
\hline $\mathrm{JR}$ & $\mathrm{KR}$ & $\mathrm{LR}$ & 20 \\
\hline $\mathrm{JO}$ & $\mathrm{KO}$ & $\mathrm{LO}$ & 0 \\
\hline $\mathrm{J} 2$ & $\mathrm{~K} 2$ & $\mathrm{~L} 2$ & -20 \\
\hline $\mathrm{J} 3$ & $\mathrm{~K} 3$ & $\mathrm{~L} 3$ & -30 \\
\hline $\mathrm{J} 4$ & $\mathrm{~K} 4$ & $\mathrm{~L} 4$ & -40 \\
\hline $\mathrm{J} 5$ & $\mathrm{~K} 5$ & $\mathrm{~L} 5$ & -50 \\
\hline $\mathrm{J} 6$ & $\mathrm{~K} 6$ & $\mathrm{~L} 6$ & -60 \\
\hline
\end{tabular}

Для ряда марок отечественных сталей по ГОСТ 27772 выбраны аналоги зарубежных сталей по стандартам системы EN (табл. 2).

Выполненное сопоставление отечественных и зарубежных сталей для металлоконструкций показывает, что в целом уровень механических свойств сталейаналогов довольно близок, отличия практически не дают существенных отличий в надежности и работоспособности металлоконструкций. В российских и европейских стандартах есть различия, связанные с металлургической технологией, обеспечивающей формирование механических свойств стальной продукции. В стандартах технологические способы не раскрываются, гарантии по регламентируемым параметрам, часто приводимые только в случаях, когда соответствующие требования оговорены в заказе на металлопродукцию, носят как бы рекламный характер. Сказанное прежде всего относится к зарубежной технической документации. В отечественной научной литературе более подробно излагаются идеи упрочнения сталей и технологические пути их решения, например, при производстве высокопрочных нелегированных. Из публикации видно, что отечественная металлургия практически освоила производство нелегированных высокопрочных углеродистых сталей на уровне, регламентируемом стандартами системы EN. Важным показателем надежности сталей отечественного производства является указанная в ГОСТах величина ударной вязкости после деформационного старения. Гарантии по ударной вязкости в состоянии 
деформационного старения являются преимуществом отечественных стандартов по сравнению с европейскими стандартами.

\section{СПИСОК ЛИТЕРАТУРЫ}

1. ТУ 14-104-133-92 «Прокат повышенной прочности для строительных стальных конструкций».

2. ТУ 14-1-5143-92 «Прокат листовой и рулонный повышенной прочности».

3. ТУ 14-105-554-92 «Листовой прокат повышенной прочности и хладноломкости».

4. ТУ 14-1-5255-94 «Прокат фасонный и толстолистовой повышенной прочности для строительных конструкций».
5. ГОСТ 27772-88 «Прокат для строительных стальных конструкций. Общие технические условия».

6. ГОСТ 19281-89 «Прокат из стали повышенной прочности. Общие технические условия».

7. EN 10025 «Hot rolled product of non-alloy structural quality and special steels. Technical delivery conditions».

8. EN 10113 «Hot rolled weldable fine grain structural quality and special steels. Technical delivery conditions».

9. EN 10027-1 «Designation systems for steels. Part 1: Steel names principal symbols».

Таблица 2

Механические свойства российских и европейских сталей-аналогов

\begin{tabular}{|c|c|c|c|c|c|c|c|}
\hline \multirow[b]{2}{*}{$\begin{array}{c}\mathrm{N} \\
\Pi / \Pi\end{array}$} & \multirow[b]{2}{*}{$\begin{array}{l}\text { Марка } \\
\text { стали }\end{array}$} & \multirow[b]{2}{*}{$\mid \begin{array}{c}\text { Термическая } \\
\text { обработка }\end{array}$} & \multirow[b]{2}{*}{$\begin{array}{c}\text { Размер, } \\
\text { мм }\end{array}$} & \multicolumn{4}{|c|}{ Механические свойства } \\
\hline & & & & $\begin{array}{c}\text { Предел } \\
\text { текучести, } \\
\text { МПа } \\
\end{array}$ & $\begin{array}{c}\text { Предел } \\
\text { прочности, } \\
\text { МПа } \\
\end{array}$ & $\begin{array}{c}\text { Относительное } \\
\text { удлинение, \% }\end{array}$ & $\begin{array}{l}\text { Ударная вязкость (KCU, } \\
\mathrm{KCV}), \text { Дж/см }{ }^{2} / \text { Работа } \\
\text { разрушения (KV), Дж }\end{array}$ \\
\hline 1 & 2 & 3 & 4 & 5 & 6 & 7 & 8 \\
\hline 1 & $\begin{array}{l}\text { C235 } \\
\text { S235JR }\end{array}$ & & $\begin{array}{l}4-20 \\
21-40 \\
<16 \\
16-40\end{array}$ & $\begin{array}{l}235 \\
225 \\
235 \\
225\end{array}$ & $\begin{array}{l}360 \\
360 \\
360 \\
360\end{array}$ & $\begin{array}{l}26 \\
26 \\
21 \\
21\end{array}$ & $\mathrm{KV}^{+20} \geq 27$ \\
\hline 2 & $\begin{array}{l}\text { C245 } \\
\text { S235J0 }\end{array}$ & & $\begin{array}{l}4-10 \\
11-20 \\
21-40 \\
<16 \\
16-40 \\
\end{array}$ & $\begin{array}{l}245 \\
245 \\
235 \\
235 \\
225 \\
\end{array}$ & $\begin{array}{l}370 \\
370 \\
370 \\
360 \\
360 \\
\end{array}$ & $\begin{array}{l}25 \\
25 \\
24 \\
26 \\
24 \\
\end{array}$ & $\mathrm{KV}^{0} \geq 27$ \\
\hline 3 & $\begin{array}{l}\mathrm{C} 225 \\
\mathrm{~S} 235 \mathrm{~J} 2 \mathrm{G} \\
3\end{array}$ & & $\begin{array}{l}4-10 \\
11-20 \\
21-40 \\
<16 \\
16-40\end{array}$ & $\begin{array}{l}255 \\
245 \\
235 \\
235 \\
225\end{array}$ & $\begin{array}{l}380 \\
370 \\
370 \\
340-470 \\
340-470 \\
\end{array}$ & $\begin{array}{l}25 \\
25 \\
24 \\
26 \\
25\end{array}$ & $\begin{array}{l}\mathrm{KCU}^{+20} \geq 29 \\
\mathrm{KCU}^{+20} \geq 29 \\
\mathrm{KCU}^{+20} \geq 29 \\
\mathrm{KV}^{-20} \geq 27\end{array}$ \\
\hline 4 & $\begin{array}{l}\mathrm{C} 275 \\
\mathrm{~S} 275 \mathrm{JR}\end{array}$ & & $\begin{array}{l}4-10 \\
11-20 \\
<16 \\
16-40 \\
\end{array}$ & $\begin{array}{l}275 \\
265 \\
275 \\
265 \\
\end{array}$ & $\begin{array}{l}380 \\
370 \\
430-580 \\
430-580 \\
\end{array}$ & $\begin{array}{l}24 \\
23 \\
22 \\
22 \\
\end{array}$ & $\mathrm{KV}^{+20} \geq 27$ \\
\hline 5 & $\begin{array}{l}\mathrm{C} 285 \\
\mathrm{~S} 275 \mathrm{~J} 2 \mathrm{G} \\
3\end{array}$ & & $\begin{array}{l}4-10 \\
11-20 \\
<16 \\
16-40 \\
\end{array}$ & $\begin{array}{l}285 \\
275 \\
275 \\
265 \\
\end{array}$ & $\begin{array}{l}400 \\
390 \\
430-580 \\
430-580\end{array}$ & $\begin{array}{l}24 \\
23 \\
22 \\
22 \\
\end{array}$ & $\begin{array}{l}\mathrm{KCU}^{-20} \geq 29 \\
\mathrm{KV}^{-20} \geq 27\end{array}$ \\
\hline 6 & C345 - 1 & & $\begin{array}{l}4-10 \\
11-20 \\
21-40 \\
<16 \\
16-40 \\
\end{array}$ & $\begin{array}{l}345 \\
325 \\
305 \\
355 \\
345\end{array}$ & $\begin{array}{l}490 \\
470 \\
460 \\
490-630 \\
490-630\end{array}$ & $\begin{array}{l}21 \\
21 \\
21 \\
22 \\
22\end{array}$ & $\begin{array}{l}\mathrm{KCU}^{-40} \geq 34 \\
\mathrm{KCU}^{-40} \geq 34 \\
\mathrm{KCU}^{-40} \geq 34 \\
\mathrm{KV}^{-20} \geq 40 \\
\mathrm{KV}^{-20} \geq 40\end{array}$ \\
\hline 7 & C345 - 2 & $\begin{array}{l}\text { нормализа- } \\
\text { ция } \\
\text { нормализа- } \\
\text { ция }\end{array}$ & $\begin{array}{l}5-10 \\
11-20 \\
21-40 \\
<16 \\
16-40 \\
41-63\end{array}$ & $\begin{array}{l}345 \\
325 \\
305 \\
355 \\
345 \\
335\end{array}$ & $\begin{array}{l}490 \\
470 \\
460 \\
630 \\
630 \\
630\end{array}$ & $\begin{array}{l}21 \\
21 \\
21 \\
22 \\
22 \\
22\end{array}$ & $\begin{array}{l}\mathrm{KCU}^{-70} \geq 34 \\
\mathrm{KCU}^{-70} \geq 29 \\
\mathrm{KCU}^{-70} \geq 29 \\
\mathrm{KV}^{-50} \geq 27 \\
\mathrm{KV}^{-20} \geq 47 \\
\mathrm{KV}^{+20} \geq 63\end{array}$ \\
\hline
\end{tabular}


Продолжение табл. 2

\begin{tabular}{|c|c|c|c|c|c|c|c|}
\hline 1 & 2 & 3 & 4 & 5 & 6 & 7 & 8 \\
\hline 8 & $\begin{array}{l}\text { C375 - } 2 \\
\text { S355ML }\end{array}$ & $\begin{array}{l}\text { термомеха- } \\
\text { ническая } \\
\text { обработка }\end{array}$ & $\begin{array}{l}4-10 \\
11-20 \\
21-40 \\
<16 \\
16-40 \\
40-63\end{array}$ & $\begin{array}{l}375 \\
355 \\
335 \\
355 \\
345 \\
335\end{array}$ & $\begin{array}{l}510 \\
490 \\
480 \\
450-610 \\
450-610 \\
450-610\end{array}$ & $\begin{array}{l}20 \\
20 \\
20 \\
22 \\
22 \\
22\end{array}$ & $\begin{array}{l}\mathrm{KCU}^{-40} \geq 39 \\
\mathrm{KCU}^{-40} \geq 34 \\
\mathrm{KCU}^{-40} \geq 34 \\
\mathrm{KV}^{-50} \geq 27 \\
\mathrm{KV}^{-20} \geq 47 \\
\mathrm{KV}^{+20} \geq 63\end{array}$ \\
\hline 9 & $\begin{array}{l}\text { C390 } \\
\text { C390K } \\
\text { S420NL }\end{array}$ & $\begin{array}{l}\text { закалка с } \\
\text { отпуском } \\
\text { или } \\
\text { нормализа- } \\
\text { ция }\end{array}$ & $\begin{array}{l}4-50 \\
4-30 \\
<16 \\
16-40 \\
40-63\end{array}$ & $\begin{array}{l}390 \\
390 \\
420 \\
400 \\
390\end{array}$ & $\begin{array}{l}540 \\
540 \\
\\
680 \\
680 \\
660\end{array}$ & $\begin{array}{l}20 \\
19 \\
\\
19 \\
19 \\
19\end{array}$ & $\begin{array}{l}\mathrm{KCU}^{-70} \geq 29 \\
\mathrm{KCU}^{-70} \geq 29 \\
\mathrm{KV}^{-50} \geq 27 \\
\mathrm{KV}^{-20} \geq 47 \\
\mathrm{KV}^{+20} \geq 63\end{array}$ \\
\hline 10 & $\begin{array}{l}\text { C440 } \\
\text { S460N }\end{array}$ & $\begin{array}{l}\text { закалка и } \\
\text { отпуск или } \\
\text { нормализа- } \\
\text { ция } \\
\\
\text { нормализа- } \\
\text { ция } \\
\end{array}$ & $\begin{array}{l}3-30 \\
31-50 \\
<16 \\
16-40\end{array}$ & $\begin{array}{l}440 \\
410 \\
460 \\
440\end{array}$ & $\begin{array}{l}590 \\
570 \\
550-720 \\
550-720\end{array}$ & $\begin{array}{l}20 \\
20 \\
19 \\
19\end{array}$ & $\begin{array}{l}\mathrm{KCU}^{-70} \geq 29 \\
\mathrm{KCU}^{-70} \geq 29 \\
\mathrm{KV}^{-20} \geq 40 \\
\mathrm{KV}^{+20} \geq 55\end{array}$ \\
\hline 11 & $\begin{array}{l}\text { C590 } \\
\text { C590K } \\
\text { S460NL } \\
\text { S460ML }\end{array}$ & $\begin{array}{l}\text { нормализа- } \\
\text { ция } \\
\text { термомеха- } \\
\text { ническая } \\
\text { обработка } \\
\end{array}$ & $\begin{array}{l}10-36 \\
10-40 \\
<16 \\
16-40 \\
40-63\end{array}$ & $\begin{array}{l}590 \\
590 \\
460 \\
440 \\
430\end{array}$ & $\begin{array}{l}685 \\
685 \\
550-720 \\
550-720 \\
550-720\end{array}$ & $\begin{array}{l}14 \\
14 \\
17 \\
17 \\
17\end{array}$ & $\begin{array}{l}\mathrm{KCU}^{-40} \geq 34 \\
\mathrm{KCU}^{-70} \geq 29 \\
\mathrm{KV}^{-50} \geq 27 \\
\mathrm{KV}^{-20} \geq 47 \\
\mathrm{KV}^{+20} \geq 63\end{array}$ \\
\hline
\end{tabular}

Механические свойства нормализованных и термомеханически прокатанных сталей при комнатной температуре

\begin{tabular}{|c|c|c|c|c|c|c|c|c|c|}
\hline \multirow{2}{*}{$\begin{array}{l}\text { Марка стали по } \\
\text { EN10027-1 и } \\
\text { ECISS IC10 }\end{array}$} & \multicolumn{2}{|c|}{$\begin{array}{l}\text { Предел прочности Rm, } \\
\text { H/мм², при толщине, мм }\end{array}$} & \multicolumn{6}{|c|}{$\begin{array}{c}\text { Минимальное значение верхнего предела } \\
\text { текучести } \mathrm{Re}, \mathrm{H} / \mathrm{Mm}^{2}, \text { при номинальной } \\
\text { толщине, мм }\end{array}$} & \multirow{2}{*}{$\begin{array}{c}\delta, \\
\% \min \end{array}$} \\
\hline & 100 & $\begin{array}{l}>100 \\
\leq 150\end{array}$ & $\leq 16$ & $\begin{array}{l}>16 \\
\leq 40\end{array}$ & $\begin{array}{l}>40 \\
\leq 63\end{array}$ & $\begin{array}{l}>63 \\
\leq 80\end{array}$ & $\begin{array}{l}>80 \\
\leq 100\end{array}$ & $\begin{array}{l}>100 \\
\leq 150\end{array}$ & \\
\hline S275N, S275NL & $370 \ldots .510 \ldots$ & $350 \ldots 480$ & 275 & 265 & 255 & 245 & 235 & 225 & 24 \\
\hline S355N, S355NL & $470 \ldots 630$ & $450 \ldots 600$ & 355 & 345 & 335 & 325 & 315 & 295 & 22 \\
\hline S420N, S420NL & $520 \ldots 680$ & $500 \ldots 660$ & 420 & 400 & 390 & 370 & 360 & 340 & 19 \\
\hline S460N, S460NL & $550 \ldots 720$ & & 460 & 440 & 430 & 410 & 400 & & 17 \\
\hline S275M, S275ML & \multicolumn{2}{|c|}{$370 \ldots 510 \ldots$} & 275 & 265 & 255 & 245 & & & 24 \\
\hline S355M, S355ML & \multicolumn{2}{|c|}{$470 \ldots 630$} & 355 & 345 & 335 & 325 & & & 22 \\
\hline S420M, S420ML & \multicolumn{2}{|c|}{$520 \ldots 680$} & 420 & 400 & 390 & 370 & & & 19 \\
\hline S460M, S460ML & \multicolumn{2}{|c|}{$550 \ldots 720$} & 460 & 440 & 430 & 410 & & & 17 \\
\hline
\end{tabular}




